\title{
Spark Joy? Compulsory Happiness and the Feminist Politics of Decluttering
}

\author{
By Laurie Ouellette
}

\begin{abstract}
This essay analyzes the Marie Kondo brand as a set of neoliberal techniques for managing cultural anxieties around over-consumption, clutter and the family. Drawing from critical discussions of consumer culture and waste, as well as feminist scholarship on compulsory happiness and women's labor in the home, it argues that Marie Kondo's "joyful" approach to "tidying up" presents pared-down, curated consumption as a lifestyle choice that depends on women's work, even as it promises to mitigate the stresses of daily life and facilitate greater well-being.
\end{abstract}

Keywords: Marie Kondo, happiness, clutter, over-consumption, neoliberalism, post-feminism, housework, danshari

Ouellette, Laurie: "Spark Joy? Compulsory Happiness and the Feminist Politics of Decluttering", Culture Unbound, Volume 11, issue 3-4, 2019: 534-550. Published by Linköping University Electronic Press: http://www.cultureunbound.ep.liu.se 
"The ideal of happiness has always taken material form in the house ..." --Simone de Beauvoir

In the debut episode of the Netflix series Tidying Up With Marie Kondo, we meet the Friend family in their suburban, one-story bungalow on the outskirts of Los Angeles. Kevin is a sales manager for a restaurant supply company who works 50-60 hours per week and "then some on the weekends." Rachel works part-time from home three days a week, while also caring for their two toddlers, Jaxon and Ryan, who is still nursing. The parents confess to fighting constantly about money and housework. Rachel is overwhelmed by the "chaos" of everyday life: With small children to watch over as well as waged labor to perform, dishes go unwashed, toys overflow the playroom, and dirty clothes pile up. Kevin resents the chronic mess, and is upset because Rachel has hired someone to help with the laundryan expense he feels they could avoid. While economic instability, overwork and an uneven division of labor in the home are on full display, the premise of the program-which is billed as a home makeover-prompts the Friends to attribute their malaise to an overabundance of household goods. Rachel is shocked when prompted to place every item of clothing she owns in a giant pile and is confronted with the scale of her wardrobe; "I want to appreciate what I have instead of needing more things," she tells decluttering expert Marie Kondo, who advises her to keep only those items that "spark joy" for her and to discard the rest. Kevin, who has fewer belongings, blames Rachel for the chronic mess, complaining about the children's overstuffed closets and protesting the excessive number of decorative pillows on the couple's bed.

Setting the template for future episodes, Rachel and Kevin, who are thirtysomething and white, are coached for six weeks on the trademarked KonMari method of "tidying up." This requires a massive purge of household possessions, followed by instruction on techniques for discarding, organizing and storing remaining household items on a daily basis. The method is based on the notion that every material object one possesses should "spark joy" - a sense of delight that is simultaneously physical and emotional--and the promise that curating the home in such a way will bring "life-changing magic" to its inhabitants. "Through tidying up, you can rethink the way you live, think about your work or your interpersonal relationships, and consider how you want to live from this point on," Kondo explains in the publicity for her blockbuster advice book The Life-Changing Magic of Tidying Up: The Japanese Art of Decluttering and Organizing (2014). Kondo enlists the Friends in a five-step process for sorting and discarding clothes, books, paper, general household items, and personal mementos. She also offers televised lessons (accentuated with graphics and close-ups) on folding and storing clothes, organizing kitchen drawers and other tidying activities. In between Kondo's visits 
to the bungalow, the Friends record themselves on cell phone cameras, capturing amateur footage of themselves as they figure out what possessions spark joy, fill dozens of oversized trash bags with throwaway items, and try to implement Kondo's methods on their own. This unpolished self-documentation is presented as an "authentic" window into the process of tidying up, and is interspersed with professionally-filmed scenes in every episode.

Given the melodramatic conventions of reality television, it is not surprising that tensions flare. Shortly into the episode, Rachel confronts Kevin, telling him that it is unrealistic to expect her to keep the house tidy. She melts down emotionally after Kondo assigns her the kitchen - the messiest room in the houseto declutter and organize. In a frustrating moment captured on her cell phone, Rachel admits-with more than a hint of sarcasm-that the KonMari method of folding laundry does not spark joy for her. By the time of the reveal, however, these resentments have been largely smoothed over. On Kondo's final visit, the Friends display their pared down closets and storage spaces, and declare a renewed sense of harmony and happiness. Rachel is exhausted, but also relieved to have confronted her consumption habits, and pleased that Kevin finds decluttering sexy and has "been more romantic lately." Both parents report that the KonMari method has reduced their bickering and allowed them to enjoy themselves more as a family. However, Rachel alone accepts responsibility for keeping up the momentum, vowing to do what it takes to "keep the good feeling going."

This essay analyzes Tidying Up with Marie Kondo as a set of techniques for managing anxieties around over-consumption, clutter and the family. Drawing from critical discussions of consumer culture and waste, as well as feminist scholarship on compulsory happiness and women's labor in the home, I argue that Kondo's "joyful" approach to downsizing household possessions does little to challenge the priorities or consequences (fast consumption, environmental damage, labor exploitation, socio-economic inequality) of free market capitalism. On the contrary, the Kondo brand, as mediated in particular by the Netflix series, presents pared-down, curated consumption as a lifestyle choice that depends on women's work, even as it promises to mitigate the stresses of daily life and generate personal well-being. As shown in the debut episode, social problems and tensions are folded into the problematization of clutter, and women in particular are called upon to solve these issues by implementing the Kondo regimen in the service of families. In sync with neoliberal and postfeminist mantras (Gill 2007, Rottenberg 2018) emphasizing choice, personal responsibility and self-empowerment over collective action and social change, the structural problems that women and families face (lack of affordable daycare, a dismantled safety net, the persistent sexual division of labor, overwork and precarity) are displaced onto the mounting "problem" of the cluttered family home. This is a problem to be solved mainly by 
women, to whom Kondo offers "not merely rules on how to sort, organize and put things away," but also a step-by-step guide to acquiring a new, more positive mindset. "Once you have experienced what it's like to have a truly ordered house, you'll feel your whole world brighten ... This is what I call the magic of tidying up. Not only will you never be messy again, but you'll also get a new start on life" (Kondo 2014: 5-7).

Just as consumption has been feminized historically, women have increasingly been called upon to solve the "unbearable heaviness" of household clutter (Luchessi 2019), which has intensified since the 1990s as a concern for researchers, psychologists, lifestyle gurus, the burgeoning decluttering industry and reality television. Targeting women as the assumed caretakers of the cluttered family home, Tidying Up with Marie Kondo presents an Eastern-inflected twist on quasi-minimalist lifestyles by linking the labor of discarding household possessions to spiritual rituals, bodily sensations, and promises of happiness. The Netflix series glosses over the gender and class politics of consumption and housework (Strasser 1999, Federici 2012), but it does propose the compelling possibility that women can work domestic and emotional "magic" by embracing Kondo's techniques for minimizing, decluttering and "tidying up." This possibility is thwarted by the conventions of reality television, which demand authenticity and melodrama signified by interpersonal conflict, trauma and emotional discord (Dubrofsky 2009). Despite Kondo's cheerleading (Toomer 2019), the packaging of her regimen as a way to transform the "chaotic lives of people at a crossroads" brings it squarely into reality television's storytelling orbit (Rose 2018). By turning the KonMari method into televised stories about real people, Tidying Up simultaneously lends entertainment value to the problematization of clutter and carries the potential to kill joy, in the sense of questioning assumptions and norms about family, gender, consumption, and happiness (Ahmed 2010). Mobilizing women's domestic labor in the service of what Sara Ahmed calls "happy objects," the Netflix series connects neoliberal and postfeminist sensibilities to her clutter-free lifestyle template, and voices (however partially) female complaints (Berlant 2008) about societal messes that decluttering cannot fix.

\section{Marie Kondo and the Problematization of Clutter}

Marie Kondo was a twentysomething, Tokyo-based professional organizer with a backlog of clients when The Life-Changing Magic of Tidying Up was first published in Japanese in 2011. An instant sensation in Japan, the book was translated into multiple languages and published in more than 30 countries; it was a bestseller in Europe prior to its 2014 publication in the United States, where it has enjoyed 144 weeks (to date) on the New York Times best seller list. This global commer- 
cial success begat the companion manual Spark Joy: An Illustrated Class on the Art of Organizing and Tidying Up (2016), as well as a manga version of Tidying $U p$ and a customizable KonMari workbook. Together, these books have sold 11 million copies worldwide and counting (Archer 2019). Kondo has become a celebrity around the world, appearing regularly in women's magazines, in a Ted Talk on YouTube, at the 2019 Academy Awards Oscars ceremony, and on television programs including The Late Show with Stephen Colbert, where she taught the comedic host how to fold a fitted sheet.

By adapting Kondo's books into a reality-based home makeover program for its international streaming platform, the Netflix original series infused televised decluttering with significantly more currency and prestige than is usually attributed to domestic how-to programming on broadcast and cable channels. Timed to coincide with the adoption of New Year resolutions, Netflix released all eight episodes of Tidying Up with Marie Kondo simultaneously on January 1, 2019. Netflix subscribers were encouraged to binge-watch the episodes, a concentrated form of viewing that bears a strong temporal resemblance to the KonMari method of tidying up, which is kick-started by a concentrated and time-consuming initial household purge. With the exception of subtitling, references to Japanese culture and an emphasis on magic and joy, Tidying Up With Marie Kondo is aesthetically and conceptually similar to most lifestyle and home makeovers. Yet, to the extent that both streaming platforms and binge-watching are associated with so-called quality programming, the Netflix drop signaled the show's presumed distinction from denigrated women's media culture (Levine 2015) and the distracted mode of television reception ascribed to housewives historically (Spigel 1992). Two Emmy award nominations further cemented the "quality" and importance of the series. The cultural legitimation of Tidying $U p$, and the extraordinary attention it has received, are partly due to Kondo's strategic partnership with Netflix, which uses its algorithms to promote the series to viewers who might not otherwise watch reality entertainment or domestic advice (especially in real-time), and distributes it to 160 countries (Trillby 2019). Unlike formatted reality programs that are customized to accommodate local tastes and cultures (Kraidy 2005), Tidying Up folds Japanese and Western (particularly US) cultural references into a generic makeover template that is presumed to be globally accessible. This approach serves Netflix's quest for international expansion (Lobato 2019) and Kondo's ambition to expand her growing global lifestyle brand: "My mission is to organize the world and spark joy in people's lives ... through this partnership with Netflix, I am excited to spread the KonMari method to as many people as possible," she told the trade press (Park 2018). As noted in the Hollywood Reporter, Kondo's quest to build a "global community" for the KonMari method complements, and is facilitated, by the ongoing globalization of Netflix, which launched the series to 117 
million subscribers worldwide simultaneously (Rose 2018).

In the United States, the January 1st release of Tidying Up generated a rapid flood of reviews, commentaries, interviews and blog posts, as well as an explosion of discussion on Twitter, Instagram, Reddit and Facebook, where female fans formed groups to describe and visually document their purging and decluttering efforts. According to news outlets, a massive national purge of household possessions triggered by the drop of the Netflix series overburdened trash collectors in the United States, while many thrift stores saw their donations quadruple-a trend that was not always appreciated as many of the items donated were deemed unsalable (Panette and Hoyle, 2019). The series further boosted sales of Kondo's books, and, capitalizing on her growing notoriety, Kondo launched a "certified training program" for KonMari consultants in the United States and expanded her lifestyle brand to dispense advice across multiple social media platforms and sell proprietary decluttering merchandise, including a 6-piece storage box set, available for $\$ 89$ on KonMari.com. In this respect, the Netflix series is just one (highly visible) aspect of a broader Kondo phenomenon that clearly resonates at this juncture of the 21 st century.

Beyond her partnership with Netflix, Kondo's high profile as a celebrity decluttering expert can be attributed to a confluence of factors, from her fusion of homemaking and Eastern spiritual traditions, to the trending of minimalist and downsized lifestyles, to discourses on the problem of clutter and its impact on families. While Kondo's approach appears novel in the US and elsewhere, she is not particularly unique in the Japanese context, where anxieties about over-consumption and material excess have a long history, and where other experts introduced many of her ideas and techniques. In Waste: Consuming Postwar Japan, Eiko Maruko Siniawer (2018) chronicles the historical tension between the desire for middle class consumer lifestyles and the promotion of "waste consciousness" as a national civic duty in postwar Japan, often through "advice doled out in newspapers, magazines and mass market books" (6). While consumer excess was initially problematized in moral and environmental terms, this way of thinking shifted in the 2000s, as neoliberal subjectivities rooted in care of the self and personal well-being became dominant. In 2009, professional organizer Yamashita Hideko coined the term danshari, defined as a "new technique for tidying up" that associated reduced consumption and decluttering with the pursuit of serenity, freedom and psychological and spiritual well-being (Siniawer 2018: 266).

Building on books like Nagisa Tatsumi's The Art of Discarding: How to Get Rid of Clutter and Find Joy (2005), which Kondo acknowledges as an inspiration, the term danshari signaled a new approach to throwing things away in Japan. Whereas earlier discourses on waste consciousness were framed by "organizations that served the communal interest" (such as government agencies and environmental 
groups), the new literature was more individualistic, promoted by "personalities whose advice for finding happiness centered on ... self-fulfillment in the present" (Siniawer 2018: 267). Danshari offered "antidote to the trauma and discord of a lifestyle overflowing with stuff," a problem that was attributed not to advertising or consumer capitalism, but to "one's own decisions" (268). According to Siniawer, this new wave of decluttering advice, of which the KonMari method has become the best-known example, is unconcerned with the exploitative labor practices underpinning the overconsumption of cheap goods or the environmental impact of this mode of production. It dismisses class differences by treating consumption habits as a choice and by assuming that discarded possessions can be replaced with more satisfying ones, and it mimics consumer logic by emphasizing the pleasure associated with consumer goods over their utility and functionality. In contrast to earlier concerns about waste, danshari encourages people to throw things away without guilt or concern for recycling or reuse, as these ethical responsibilities can be "obstacles in the quest to discard." Siniawer could easily be describing a scene from any episode of Kondo's Netflix series when she notes that the "amount of garbage produced through decluttering" is taken as "evidence of the success of both the person ... and the technique itself" (Siniawer 2018: 269).

The Life-Changing Magic of Tidying Up drew from and adapted the danshari phenomenon in Japan, but its message resonates with discourses about consumption and waste in the United States. As Susan Strasser (1999) has shown, waste is largely a $20^{\text {th }}$-century problematization-in early America, nearly everything was reused. With the rise of mass production and advertising, goods became fashionable and disposable; corporate strategies like planned obsolescence, fast production and niche marketing intensified the cycle. This has generated vast quantities of trash unimaginable in earlier decades, as well as anxieties about how to deal with unwanted goods. Unlike Japan, in the United States, aside for short-lived anti-waste and rationing campaigns in the 1920s and 1940s, the problem of over-consumption has always been individualized. As Strasser astutely notes, only the wealthy and the comfortably middle class can afford to be wasteful, and discarding things can be a "way of demonstrating power." Throwing away items that still have use value creates and legitimates "social differences based on economic status" (Strasser 1999: 9). Regardless of intentions, donating to charities or thrift stores assumes perpetually needy populations (in and outside the U.S., where donations are often shipped) distinct from consumers who browse secondhand shops for fun or are thrifty by choice (Strasser 1999: 9, Lezotte 2017). Tidying Up With Marie Kondo perpetuates these class hierarchies, but the series also works on an aspirational level, presenting Kondo's method of discarding surplus goods as a means to a quasi-minimalist lifestyle based on volition, not necessity. Translating danshari for a Western audience, the series promotes sorting and discarding as 
a path to individual well-being and does not encourage secondhand reuse. This allows privileged consumers to adopt a throwaway ethic with no concern for the societal impact. Because this message is out of sync with middle class culture of garage sales, thrift stores, recycling and ethical consumerism, many U.S. viewers have nonetheless flooded donation centers with so much waste that a term was coined-"the Kondo effect"-to describe the show's impact on charities used as dumping grounds for unwanted consumer goods.

The Netflix series narrativizes the sorting and discarding process, and infuses it with drama and surprise. In every episode, the vast quantity of clothing, shoes, housewares, toys, papers, and mementos discarded by the families is marveled upon, visually emphasized through camerawork, and praised by Kondo. Shots of overstuffed trash bags filled with unwanted goods are prolific in all the episodes, but discussions of where this material goes after the decluttering process are nonexistent. The fetishization of waste in quantified terms can take on a competitive element in fan-based Facebook groups, where Kondo followers chronicle their purges for others, post photographs, and reveal the quantity of garbage bags filled. What is particularly novel about the KonMari method for Western audiences, is its engagement with Eastern spiritual traditions including the Shinto religion and animism. According to Sokyo Ono, Shinto is an indigenous Japanese faith that revolves around the "celebration of events of daily life, great and small" (2004: 90). Shinto shrines are communal sites of everyday life, and are believed to generate a "tingle of excitement, a thrill of joy" in those who encounter them. Shinto also involves kami, objects of worship that are revered and respected (Ono 2004: 90-91). Kondo, who served in a Shinto temple as a teenager, draws from these traditions in her approach to inanimate objects and emphasis on sparking joy. She attributes a mystical essence to things, which must be physically touched to determine whether they spark joy, and which must be thanked for their service if they end up in the discard pile. In each episode of Tidying Up, Kondo kneels on the floor to greet the home as a type of shrine, while the inhabitants observe (and sometimes take part in) the ritual. While this incorporation of indigenous Eastern spiritual traditions lends some credence to Kondo's characterization of tidying up as a type of magic, the rituals are never explained or even contextualized. By incorporating bits and pieces of ancient Japanese culture into the reality television home makeover, Tidying Up allows participants and viewers alike to appropriate the "other" (hooks 1984, Valdivia 2017) for their own pleasure and purposes. Kondo, who speaks some English but communicates primarily in Japanese, is translated and subtitled on the series-an unusual practice for American viewers, given the highly US-centric nature of broadcast and cable television. But this opening up of linguistic diversity is undermined to the extent that her selective engagement with Eastern spiritual traditions is deracialized, secularized and shorn of history. 
Kondo translates danshari for Western (especially US) consumers caught in the tensions and contradictions of postfeminism and late capitalism, offering novel and exoticized techniques for navigating relations between people and objects.

While Kondo's books link decluttering to a range of happy outcomes, from weight loss to career success, the Netflix series is focused almost entirely on family well-being. The program courts a universal appeal to frazzled and unhappy families and couples, especially women and mothers. In the opening vignettes, scenes of household clutter and domestic chaos are overlaid by a cacophony of voices complaining about chronic stress and proclaiming "we have too much stuff." Kondo appears as an off-screen announcer to declare a "war on clutter," after which she cheerfully declares, "I love mess." It soon becomes clear that what she actually enjoys is disseminating her methods, as footage from her Ted Talk and photographs of her advice books flash across the screen. Kondo introduces her branded method of tidying up from a sparse and exceptionally tidy living room; this calm and serene scene is juxtaposed with footage of an agitated woman-a participant on one of the episodes--engulfed by mounds of household goods. She is crying. When a happier, much more composed female participant from a different episode appears on screen, the viewer is assured that a transformation is about to take place. Going into the episode, we hear her assurance, "Marie brought a whole lot of joy upon our home."

It is not surprising that women figure so prominently in the opening credits. As Siniawer points out, the deeply gendered orientation of danshari bridges global differences, to the extent that "historically and to this day, women everywhere are disproportionately called upon to take on the role of consuming as well as discarding consumption's detritus" (2018: 297). This is certainly the case in the United States, where clutter and its impact on American families has become an increasingly pressing concern for social scientists and popular media culture alike. The discourse problematizing the "war on clutter" is exemplified by prominent research study of 32 dual-income, middle class families with school-aged children in the greater Los Angeles area. Anthropologists at the Center on Everyday Lives of Families at the University of California, Los Angeles carefully observed the families, tracked their activities, and took hundreds of photographs of their homes and possessions, which were eventually collected as a book. They interviewed the subjects extensively and tested their saliva to measure cortisone levels. Not unlike a reality television show, the study claimed to reveal the "realities" behind the closed doors of the home in the $21^{\text {st }}$ century, with a particular emphasis on family consumption and material culture. Accentuating the connection to reality television, they captured their findings in a video that now appears on YouTube. To their dismay, but not surprise, the researchers claim to have found over-stressed households "overflowing" with material possessions (Arnold et al 2012). Accor- 
ding to their report, three out of four garages were too full of household goods to hold cars, stockpiles of convenience food were observed, and quality family time was scarce. These findings are unsurprising to anyone navigating the demands of work and parenting. But instead of placing the shared experience of the families within a broader social, political and economic context, the researchers isolated household clutter as the problem--and gendered both the cause and the solution. A passage quoted in numerous news stories exemplified the magnitude of the issue by describing the consumer excess of a teenage girl's bedroom, where "165 Beanie Babies, 36 figurines, 22 Barbies, and 20 other dolls" were found (Siniawer, 2018: 302). According to researchers, "managing the volume of possessions" had become such "such a crushing problem in many homes that it elevated levels of stress hormones for mothers"-a claim that was not situated within the gender politics of domestic labor (Arnold et al 2012, Feuer 2012) or the rise of post-feminism, which insists on female choice and empowerment but offers no solution to lingering gender inequalities. As news spread that families in the United States were becoming "prisoners of their own clutter," popular media perpetuated this tendency to simultaneously highlight and obscure the role of gender (Teitell 2012, 2018). As long as women are held disproportionately responsible for the care and well-being of families despite the realities of the dual-income workforce (Hochschild 1989/2003, Brown 1993), managing the "excesses" of household consumption, as with other forms of housework and care work, can be characterized as a female problem.

Since the 1990s in the United States, a growing industry has responded to, and perpetuated, the gendering of clutter, promising women the knowledge, motivation, merchandise and skills to manage the chaos of domestic life through the sorting and organization of household objects. Books, magazine articles, websites, blogs, apps and YouTube videos devoted to clutter have proliferated, and a new occupation-the decluttering expert-has emerged. Reality television has also intervened, with lifestyle and home makeover programs like Clean House, Clean Sweep and Mission: Organization-as well as tie-in books and merchandise-advising mothers to consume less, simplify, declutter and organize domestic space. The Kondo phenomenon took hold in the United States in a cultural climate in which clutter was already feminized and problematized as a looming threat to the functionality and happiness of the family. Unlike much of this earlier advice, Kondo does not scold or shame mothers, nor does she offer time-saving, multi-tasking techniques (Nathanson 2013) to make women's work more efficient. Instead, Tidying Up proposes that minimalist decluttering will bring pleasure and well-being to women and families. 


\section{Happiness and the Re-Valorization of Housework}

Six of the eight episodes of Tidying Up with Marie Kondo focus on heterosexual families in states of crisis (the other two episodes feature young queer couples who declutter as a means of achieving adulthood and solidifying their newly-formed family unit). The impetus for Kondo's intervention is not just household mess, but also encompasses problems ranging from marital tensions, to the need to make space for a new baby, to the trauma of downsizing from a home to an apartment. While it would have been possible to target cosmopolitan singles or childless couples looking to minimize and self-renew as the ideal subjects of Kondo's method, the Netflix series does not take this approach. Indeed, the episodes have little concern for aesthetics or style; the reveal of an organized closet or silverware drawer lacks the visual pleasure as well as the aspirational consumer desire circulated by most lifestyle porn. The homes Kondo visits are ordinary, and sometimes drab, filled with unremarkable furniture, mass-produced decorations, and of course, piles of papers, boxes and bins. Kondo tailors her method to the families struggling behind the walls of these homes, telling participants (and by extension, viewers) that "couples can deepen their ties through tidying," gushing over crabby babies and children, tailoring the KonMari method to specific family situations, and empathizing with mothers in particular (Kondo has two small children). However, the magic of tidying up, as a means to greater ends, does not happen on its own. Across the episodes, mothers and wives disproportionately shoulder the physical and emotional labor of the KonMari method and the project of family happiness within which it is situated.

Feminists have long contested the sexual division of labor normalized by $\mathrm{Ti}$ dying $U p$ and other lifestyle and reality television programs. While the labor of cleaning, cooking and child-rearing is unwaged, feminists contend that it is foundational to the social reproduction of capitalism and its subjects (Spigel 1992). The refusal to perform this labor, and to demand wages for housework, was a crucial though largely unrealized element of the global 1970s women's movement (Federici 2012). Even as a post-feminist sensibility that assumes that women are now empowered has taken hold (Gill 2007, McRobbie 2008), the persistent gendering of household chores remains a sore spot. Sociologists point out that even as most women have entered the paid workforce and held "equally accountable" to the historically male breadwinner ethic (Fraser and Gordon 1997), they are still disproportionately responsible for a "second shift" of labor in the home (Hochschild, 1989/2003). This labor is not limited to housework, but also includes the emotional and care work (what Federici calls reproductive labor) performed by women within family relationships. Women's work also encompasses the labor of consumption. As Celia Lury argues, women are not only the primary shoppers for families, they are also expected to "go to work" on goods that are bought-in 
this sense, women are the "producers of goods and services" of which husbands and children are the final users (1988: 121). This expectation fits neatly with the gendering of minimalist discarding and decluttering on Tidying Up With Marie Kondo.

The multi-faceted labor that women perform in the service of families has become even more crucial in neoliberal societies where safety nets and social service provisions have dwindled and individuals are expected to facilitate their own well-being. Within the current stage of capitalism, families are expected to buffer the shocks of the free market, absorbing the risk of illness and financial insecurity, providing the care no longer conceived as a collective right, and nurturing the human capital of self-enterprising workers and citizens (Ouellette \& Wilson 2011, Wilson and Chivers 2017). In the wake of privatization and growing precarity, women's work is needed to nurture and stabilize family units; the family remains normative (and becomes more inclusive) because it has become a private alternative to social welfare (Duggan 2003). While women bear the primary burden of this heightened emphasis on the family, the labor performed by women for families is complicated by the notion that it is also considered a "labor of love" (Lury 1988: 127). Decluttering the family home is not the same as working for wages in a factory or an office, which makes the feminist critique of the second shift all the more complex and urgent. As Silvia Federici argues, women's work is "where the contradictions inherent in alienated labor are most explosive, which is why it is the ground zero for revolutionary practice" (2012: 3).

As I have detailed elsewhere, a large swath of lifestyle and reality television revolves around advising, prodding and assisting mothers as they navigate the demands of the second shift and the shocks of neoliberalism (Ouellette 2016). In many respects, Tidying Up exemplifies and perpetuates this mode of late capitalist governmentality, exemplified by an episode revolving around the African-America Mersier family-Douglas and Katrina and their pre-teenagers Kayci and Nolan-who have downsized from a large suburban house to a small 2-bedroom city apartment. Every room in their new home is bursting with musical instruments, DVDs, clothing and other possessions; stress levels are high, and space is minimal. Only Katrina knows where to find what is needed amidst the chaos: "She bears a lot of the weight of keeping the house organized," Douglas says of his partner, who has initiated the KonMari makeover. While both parents work outside the home (Douglas is a musician, Katrina is a hair stylist), Katrina also does the cooking and cleaning. She also absorbs the trauma of downsizing, worrying constantly about its impact on the children. "I feel like I'm to blame, because I'm the mom," she tells the camera. "Mom is supposed to keep home. My responsibility is to do the laundry, go to the grocery store, create a home ... with peace of mind." The Mersiers begin the purging process with Katrina firmly at the helm; she even does the 
children's KonMari "homework" for them. When Kondo teaches Katrina to fold sheets into small and precise rectangles, she suggests teaching the whole family to be responsible for their belongings, suggesting that "learning to tidy up" is important to the children's future. By the end of the episode, it is clear that Katrina's lesson has less to do with the technicalities of decluttering and organizing than with the affirmation of the importance of her labor and the socialization of her offspring - a feat she captures on her cell phone at the laundromat, where they are filmed folding their own clothes. Even Douglas, who has boasted about never cooking and barely setting foot in the overcrowded kitchen, is glimpsed washing dishes in a brief scene near the conclusion of the episode. While the apartment is still cramped-and we are led to assume that Katrina will still be needed to keep life for the Mersiers running smoothly-she feels the "joy and peace of her new home" for the first time. For Katrina, this is happiness.

Katrina's happiness speaks a paradox discussed by Wendy Brown. As Brown argues, women are contradictorily positioned within neoliberal capitalist societies. The naturalization of families as the site of social reproduction means that women can never become the self-fulfilling individuals that men are imagined to be, for they have been positioned as selfless subjects who exist to care for others (Brown 1995: 148). Tidying Up pays lip service to this dilemma by asking men to take part in the televised portion of the KonMari method, but the episodes also make clear that discarding and decluttering, and the physical and emotional labor it represents, is women's work. What is compelling about Kondo is how she "valorizes," to use Federici's term, this labor, not through wages but by associating decluttering with pleasurable and affirmative affects. Because most women work for pay out of necessity in jobs that may not be pleasurable or rewarding, this affirmation carries a different resonance than the second-wave feminist critique of the illusory happy housewife (Ahmed 2010, Friedan 1963). At a juncture when happiness is promoted by governments, researchers, psychologists and marketers as a compulsory aspect of the ongoing project of the self (Davies 2015, Binkley 2014, Cedestrom 2018), Kondo's promise to bring joy to the laundry room, the kitchen, and the garage connects tidying up to idealized forms of neoliberal subjectivity that often exclude mothers. Kondo's claim that household objects can spark joy brings the quest to achieve happiness into the mundane spaces of everyday life. In her books, Kondo concedes that most people will need training to develop a sensitivity to joy as she understands it. In every episode, she demonstrates what it feels like when an object sparks joy by jumping in the air and making a "ching" sound-a bodily performance of jouissance in the Barthian sense (Barthes 1973). The small pleasures of television reception associated with the housewife's routinized chores have given way to binge-watched makeover programs that connect pleasure to women's work in different ways. 
Of course, as feminist scholars like Sara Ahmed argue, feelings like happiness are ultimately socially constituted. The capacity of objects to spark orgasmic-like pleasure is contingent on the circulation of ideology and affect. If we "think of instrumental goods as objects of happiness, important consequences follow. Things become good, or acquire their value as goods, insofar as they point toward happiness. Objects become happiness means," Ahmed contends (2010: 26). Happiness is not inherently good, in other words, but is often a means of "encouraging us to line up with things in the right way" (2010: 37). Because Tidying Up does not address the broader politics of consumer capitalism or gender inequality, heightened sensitivity to joy (experienced through objects) can easily be aligned with the imperative to replace functional but unjoyful consumer goods with newer, shiner, more pleasurable possessions-which in turn prompts the need for decluttering as women's work. Ahmed raises another point about the family that is applicable here. While the concept of the happy family is preloaded with positive connotations, the happy family is "also an object (something that affects us, something we are directed toward) and something that circulates through objects." The family becomes a "happy object through the work that must be done to keep it together" (2010: 46). We see this work at play in an episode featuring Wendy and Ron Akiyama, a fifty-something, Japanese-American couple whose adult children are no longer living at home. While spacious, their house is bursting with Christmas decorations, clothing, baseball cards and memorabilia. Kondo predictably teaches them to sort through the mess, determine what possessions spark joy, and discard everything else. Wendy takes enormous pleasure in her huge collection of holiday ornaments; the joy they spark for her is connected to a fond memory of her mother, from whom she learned to stage elaborate holiday celebrations for her children.

Wendy also enjoys a large clothing collection, much of it unworn, which fills an entire spare bedroom. These items do not spark joy in the same way. Wendy likes her wardrobe, but admits to using retail therapy to destress after fighting with Ron, and as a way to "hit him in the pocketbook." She tells Kondo that she hopes that "tackling something together" will bring them closer as a couple, but Ron is less enthused. In fact, he admits that participating in the program was "not his idea" and that he's not 100 percent in it. Indeed, Ron is so hesitant that his grown son arrives on the scene, in the hopes his parents can use the TV production as a way to "get to know each other in a new way." The family as a happy object is mediated by the sorting and purging of goods according to the KonMari method, some of which spark joy, others which have become burdensome and disordered. The family must be worked on, stabilized, and ultimately renewed by Wendy's diligent decluttering. Wendy's commitment to tidying up despite Ron's less-than-positive attitude glosses over but cannot entirely erase her prior attempts to sabotage 
the happy object, or even kill joy (Ahmed 2010), by overspending as a gendered form of revenge. Wendy's orientation to the KonMari method directs the happiness sparked by treasures found among decades of accumulation to the preservation of the family unit. Dozens of trash bags are successfully removed from the home; where the discarded contents end up is not a concern of the series or the Akiyamas. Per the narrative arc of reality television, Ron eventually agrees to sort through his collection of baseball cards and becomes happy; when Kondo arrives for her final inspection, they are beaming. But as is often the case with "real life" entertainment, we are left wondering about the requisite happy ending-whether it will stick, whether it was worth the purge.

\section{Untidy: A Coda}

For the past year, I have been trying to declutter my own home, without much success. Over-stuffed closets, bins of outgrown toys and children's schoolwork, towering bookshelves, and scattered and disorganized photographs loom large as unfinished projects and obstacles to my own self-project of family and motherhood. For this reason, I am attracted to Marie Kondo's advice, even as I critique its maneuvers and affective ruse. The past few months I have been drawn to the multiplying Facebook groups inspired by the KonMari method, to see how others (almost exclusively women) engage with Kondo's advice. These stories, and the before and after narratives and images that accompany them, chronicle a reality far messier than the Netflix series. While fans take pride in the small achievements of tidying up and often validate each other's labor, shared anxieties about mounting clutter are never resolved, and women's work is never done. "I spent six months of my maternity leave KonMari-ing. Went from clothes to sentimental but didn't get a chance to do the garage or the computer. I still feel like my house is a mess. What did I do wrong? Feeling kinda defeated," wrote a female member of the KonMari Method Support Group. Given my own failure to tidy up, I've come to enjoy such confessions of ambivalence and failure, and the solidarity of the shared experience these admissions constitute. Untidiness signified by a chaotic surplus of household goods is not a personal choice, but a manifestation of late capitalism, including women's unrelenting double shift. Kondo's affective promises are highly compelling, but they cannot cure (or fully obscure) this mess. Indeed, in the absence of societal solutions to problems of overconsumption, precarity and overwork currently displaced onto the family unit, the KonMari method may ultimately kill joy, as much as it sparks women's desire to conform.

Laurie Ouellette is Professor at the University of Minnesota, where she teaches media and cultural studies. She writes about neoliberal cultural formations, media 


\section{Culture Unbound}

Journal of Current Cultural Research

and governmentality, and precarity, and is the author or editor of several books, including most recently Lifestyle TV (2016) and Keywords for Media Studies (2017, with Jonathan Gray). E-mail: ouell031@umn.edu

\section{References}

Ahmed, Sara (2010): The Promise of Happiness, Durham and London: Duke University Press.

Archer, Sarah (2019): “Tidying Up with Marie Kondo Isn't Really a Makeover Show," The Atlantic, 4 January 2019: https://www.theatlantic.com/entertainment/archive/2019/01/tidying-up-with-marie-kondo-netflix-show-kon-mari-review/579400/, (accessed 1/8/2019).

Arnold, Jeanne E., Anthony P. Graesch, Enzo Ragazzini, and Elinor Ochs (2012): Life at Home in the Twenty-First Century, Los Angeles: Cotsen Institute of Archaeology Press.

Barthes, Roland (1975): The Pleasure of the Text, New York: Hill and Wang.

Berlant, Lauren (2008): The Female Complaint: The Unfinished Business of Sentimentality in American Culture, Durham: Duke University Press.

Binkley, Sam (2014): Happiness as Enterprise: An Essay on Neoliberal Life, Albany: SUNY Press.

Bresford, Trillby (2019) "Netflix Phenomenon 'Tidying Up with Marie Kondo' was Nearly a Scripted Series," The Hollywood Reporter, 17 January, 2019: https:// www.hollywoodreporter.com/live-feed/tidying-up-marie-kondo-was-a-scriptedtv-series-1176727, (accessed 2/15/2019).

Brown, Wendy (1995): States of Injury, Princeton: Princeton University Press.

Cedestrom, Carl (2018): The Happiness Fantasy, London, Polity 2018.

Chayka, Kyle (2019) "The Exhausting Minimalism of Tidying Up," The New Republic, 11 January, 2019: https://newrepublic.com/article/152878/exhausting-minimalism-tidying-up-netflix-marie-kondo, (accessed 2/8/19).

Davies, William (2015), The Happiness Industry: How the Government and Big Business Sold Us Well-Being, London: Verso.

Dubrofsky, Rachel E. (2009): "Fallen Women in Reality TV," Feminist Media Studies, 9.3,353-368.

Duggan, Lisa (2004): The Twilight of Inequality? Neoliberalism, Cultural Politics and the Attack on Democracy, Boston: Beacon.

Federici, Silvia (2012): Revolution at Point Zero: Housework, Reproduction and Feminist Struggle, Oakland, CA: PM Press.

Feuer, Jack (2012): "The Clutter Culture.” UCLA Magazine. 1 July, 2012: http://magazine.ucla.edu/features/the-clutter-culture/, (accessed 4/2/19).

Fraser, Nancy \& Linda Gordon (1997): "A Genealogy of Dependency: Tracing a Keyword of the U.S. Welfare State." Nancy Fraser (ed), Justice Interruptus: Critical Reflections on the Postsocialist Condition, New York: Routledge, 121-150.

Friedan, Betty (1963): The Feminine Mystique, New York: W. W. Norton and Company.

Gill, Rosalind (2007): "Postfeminist Media Culture: Elements of a Sensibility", European Journal of Cultural Studies, 10.2, 147-166.

hooks, bell (1992): Black Looks: Race and Representation, Boston: South End Press.

Hochschild, Arlie (1989/2003): The Second Shift, New York: Penguin.

Kondo, Marie (2014): The Life-Changing Magic of Tidying Up: The Japanese Art of Decluttering and Organizing, New York: Ten Speed Press.

Kondo, Marie (2016): Spark Joy: An Illustrated Master Class on the Art of Organizing and Tidying Up, New York: Ten Speed Press. 


\section{Culture Unbound}

Journal of Current Cultural Research

Kraidy, Marwan (2005): Hybridity: The Cultural Logic of Globalization, Philadelphia: Temple University Press.

Levine, Elana (ed.) (2015): Cupcakes, Pinterest and Ladyporn: Feminized Popular Culture in the Early Twenty-First Century, Urbana: University of Illinois Press.

Lezotte, Jennifer (2017): From Goodwill to Grunge: A History of Secondhand Styles and Alternative Economies, Durham: University of North Carolina Press.

Lobato, Ramon (2019): Netflix Nations: The Geography of Digital Distribution, New York: NYU Press.

Luchessi, Emilie Le Beau (2019): "The Unbearable Heaviness of Clutter," New York Times, 3 January 2019: https://www.nytimes.com/2019/01/03/well/mind/clutter-stress-procrastination-psychology.html, (accessed 2/8/2019).

Lury, Cecilia (1988): Consumer Culture, London: Polity.

McRobbie, Angela (2008): The Aftermath of Feminism: Gender, Culture and Social Change, Thousand Oaks and London: Sage.

Nathanson, Elizabeth (2013): Television and Postfeminist Housekeeping: No Time for Mother, New York and London: Routledge.

Ono, Sokyo (2004): Shinto: The Kami Way, Clarenton, VT: Tuttle Publishers.

Ouellette, Laurie (2016): Lifestyle TV, New York and London: Routledge.

Ouellette, Laurie \& Julie Wilson (2011): "Women's Work: Affective Labor and Convergence Culture," Cultural Studies, 25.4-5), p. 548-565.

Pannett, Rachel \& Rhiannon Hoyle (2019): "Marie Kondo Isn't Sparking Joy for Thrift Stores," Wall Street Journal, 6 March 2019: https://www.wsj.com/articles/marie-kondo-persuaded-you-to-jettison-your-junk-thrift-stores-sayenough-11551889124, (accessed 3/14/2019)

Rottenberg, Catherine (2018): The Rise of Neoliberal Feminism, Oxford: Oxford University Press.

Rose, Lacey (2018): "Netflix Orders Reality Show from Organization Guru Marie Kondo," The Hollywood Reporter, 14 February, 2018: https://www.hollywoodreporter.com/live-feed/netflix-orders-reality-show-organization-guru-marie-kondo-1084167, (accessed 2/22/2019).

Spigel, Lynn (1992): Make Room for TV: Television and the Family Ideal in Postwar America, Chicago: University of Chicago Press.

Siniawer, Eiko Maruko (2018): Waste: Consuming Postwar Japan, Ithaca and London: Cornell University Press.

Strasser, Susan (1999): Waste and Want: A Social History of Trash. New York, Metropolitan Books.

Tatsumi, Nagisa (2005): The Art of Discarding: How to Get Rid of Clutter and Find Joy, New York: Hatchett Books.

Teitell, Beth (2018): "40 Years into the War on Clutter, and We're Still Overwhelmed by Stuff," Boston Globe, 27 March, 2018: https://www.bostonglobe.com/ metro/2018/03/27/years-into-war-clutter-and-still-overwhelmed-stuff-what-going/ R9jktrIH2ySut5cMCHOSoM/story.html, (accessed 5/02/2019).

Teitell, Beth (2012): “Today's Families Are Prisoners of their own Clutter," Boston Globe, July 09, 2012: https://www.boston.com/culture/relationships/2012/07/10/ todays-families-are-prisoners-of-their-own-clutter, (accessed 5/02/2019).

Toomer, Jessica (2019): "Tidying Up is the Latest Push for Reality TV's Positivity," The Hollywood Reporter, 14 January 2019: https://www.hollywoodreporter.com/ live-feed/tidying-up-is-latest-example-reality-tvs-push-positivity-1175932, (accessed 2/08/2019).

Valdivia, Angharad N (2017). "Othering.” Laurie Ouellette \& Jonathan Gray (eds): Keywords for Media Studies, New York: NYU Press: 133-135.

Wilson, Julie \& Emily Chivers Yochim (2017): Mothering through Precarity: Women's Work and Digital Media, Durham: Duke University Press. 